\title{
ALGUNAS NOTAS SOBRE LOS FONDOS BIBLIOGRÁFICOS FRANCESES UBICADOS EN LAS PROVINCIAS
}

Sabido es que las bibliotecas de París son bastante importantes para los americanistas. Los investigadores de la época prehispánica conocen el famoso fondo Goupil-Aubin de la Biblioteca Nacional o el Codex Borbonicus llamado así porque está en la biblioteca de la Asamblea Nacional, el llamado "Palais Bourbon". Para trabajos sobre épocas posteriores, podemos dar como ejemplo los fondos del Ministerio del Ejército en Vincennes. Pero las riquezas parisienses ${ }^{1}$ tienden a ocultar las del resto de la República que tampoco son despreciables. Ciertos lectores ignoran, tal vez, que en Nantes está el archivo del Consulado de Francia en Cádiz entre 1703 y 1903, que Ruán tiene un fondo brasileño antiguo, que Lyon conserva algo de los numerosos libros en español que se imprimieron allí en tiempos pasados, etcétera.

Hoy vamos a escoger dos ejemplos bastante dispares: un fondo del Estado, el de Estrasburgo, capital de Alsacia, provincia francesa desde el siglo XviI con cuarenta y siete años de interrupción (1871-1918), y un fondo privado, el del centro "Les Fontaines", en Gouvieux, cerca de Chantilly, a unos cuarenta kilómetros al norte de París, que pertenece a la orden de los jesuitas.

El primer establecimiento se llama "Bibliothèque Nationale et Universitaire de Strasbourg' y posee unos 3 millones de volúmenes. Durante toda su historia se ha aprovechado de la situa-

${ }^{1}$ Existe ahora un nuevo fondo de 12000 libros o documentos que se está acabando de catalogar en 1991, es el "Fonds Batallion" del Collège de France. Marcel Bataillon (1895-1977), padre del hispanismo francés moderno, y gran americanista, fue también administrador durante diez años del prestigioso establecimiento fundado en el siglo XVI. Se conserva allí su obra entera (recordemos que Antonio Alatorre es el traductor de Erasme et l'Espagne, 1937), las correspondientes reseñas y una enorme documentación personal, con un $60 \%$ de separatas, clasificada por temas. 
ción fronteriza de Alsacia entre el mundo germano y el mundo francés. Estrasburgo fue el gran centro intelectual de Renania. Gutenberg y Goethe vivieron allí. También se benefició de la proximidad de tres centros intelectuales de primer orden: Sélestat en Alsacia, Basilea en Suiza y Saint-Dié, lugar de bautizo de América $^{2}$ que se encuentra en Lorena, pero no lejos de la frontera alsaciana. Al profesor Jacques Lafaye, que enseñaba entonces en la Universidad de Estrasburgo, se debe la iniciativa de mandar hacer el catálogo del fondo antiguo americano ${ }^{3}$ que consta de 1257 volúmenes, muchos en latín, un gran número en francés o en alemán, bastantes en italiano o en español, algunos en neerlandés o en sueco, y unos pocos en inglés.

El principal tema de interés son los viajes. Significativo es el gran número de tomos de Alejandro de Humboldt: treinta y ocho, casi tantos como en la Biblioteca Nacional de París ${ }^{4}$. Hay mucho sobre navegación, ciencias naturales, también idiomas americanos y temas afines. Por ejemplo, encontramos allí seis tomos del jesuita Juan Ignacio de Molina, conocido como el "Abate Molina" después de la supresión de la Compañía: Saggio sulla storia naturale del Cile (1782) y Saggio sulla storia civile del Cile (1787) con sus respectivas traducciones al francés y al alemán. Para buscar ejemplos mexicanos, hay allí un Clavijero en alemán y no menos de tres ejemplares del diccionario náhuatl-español de Alonso de Molina, el franciscano del siglo Xvi que había llegado muy niño a la Nueva España, y había aprendido el idioma jugando con los niños indios.

No es necesario dar más detalles sobre este fondo; basta con remitir al catálogo. La segunda biblioteca que vamos a describir no tiene acabado todavía el fichero de materias y da lugar a más posibilidades de hallazgos imprevistos.

Después de la Segunda Guerra Mundial, la Provincia francesa de los jesuitas decidió reunir en el centro llamado "Les Fontaines" sus mejores fondos en materia de "divinas y humanas letras', El resultado fue un conjunto de unos 600000 volúmenes que hasta 1970 sirvió únicamente para la formación de los futuros jesuitas y posteriormente ha sido abierto al público, también

${ }^{2}$ Allí, se publicó el libro donde Waldseemüller escogió a Américo Vespucci como epónimo.

${ }^{3}$ Catálogo realizado en 1968 por María E. Arias López. Prefacio de Jacques Lafaye.

${ }^{4}$ En París existe solamente una colección completa de la obra de Humboldt: en el "Institut de France", la sede de las academias. 
mantiene ahora acuerdos de cooperación con la Universidad Pública de Amiens, al norte de París.

Atrae principalmente a los investigadores de teología, filosofía y letras clásicas, pero también a los historiadores a causa de la política compradora de los bibliotecarios de la orden desde su restauración. Ellos no se han contentado con reconstituir, en la medida de lo posible, los fondos que existían antes de la disolución de 1773, y almacenar a los autores jesuitas, sino que se han interesado por todas las sociedades humanas en las cuales proyectan desarrollar su acción. Desde luego los enemigos de los jesuitas les interesan tanto como sus amigos ${ }^{5}$, y los periodos conflictivos más que las épocas tranquilas. Con motivo del bicentenario de la Revolución Francesa, se ha podido realizar un catálogo de 6000 libros o documentos, bastantes de ellos de rareza excepcional; por razones análogas, los libros sobre la zona del Caribe durante todo el periodo de las Revoluciones y del Imperio napoleónico son especialmente numerosos. Si buscamos otro ejemplo posterior, constatamos que las crisis relacionadas con la construcción del canal de Panamá llamaron también la atención de los jesuitas.

¿Cuál puede ser entonces el lugar de Iberoamérica en este tipo de fondo? No el mayor, seguramente. Extremo Oriente en que el papel de los jesuitas fue tan destacado y conflictivo se ve representado por unos 1200 volúmenes, Hispanoamérica por unos 360 , apenas más que Canadá y el conjunto de América del Norte.

Pero el interés cualitativo de estos libros es innegable. Algunos son una verdadera rareza: diez "cartas anuas" del siglo XVI ${ }^{6}$. Otros tesoros como la edición príncipe de la Brevisima relación de la destrucción de las Indias de Bartolomé de Las Casas (Sevilla, 1552), - la de la Historia verdadera de la Conquista de la Nueva España de Bernal Díaz del Castillo (ed. Remón, 1632) son interesantes, pero no únicos ${ }^{7}$.

${ }^{5}$ Afirman los bibliotecarios que el ramo de panfletos anti-jesuitas es excepcional...

${ }^{6}$ Frente a 240 que proceden de otras partes del mundo. Encontramos también una de 1603 procedente de Filipinas. Esta costumbre que tenían los jesuitas de mandar reseñas llamadas "cartas anuas" a la autoridad central es un bello regalo para los estudiosos de ahora. Por lo general, van redactadas en latín o en italiano.

${ }^{7}$ No hay fondo específico de literaturas hispánicas, pero hay muchos historiadores y cronistas, en español o en traducción. Gómara, Solís, etc. Los mexicanistas especializados en el mundo eclesiástico pueden encontrar cosas 
El fondo de Chantilly interesa también a los investigadores por la concentración de documentos sobre ciertas épocas. La zona ya aludida del Caribe en la época de las Revoluciones es fundamentalmente internacional, es decir hispanista también. El acervo de testimonios de viajeros franceses de todo el siglo XIX es muy grande. Se podrían aducir más ejemplos.

A fin de cuentas, el interés específico de esta biblioteca para los americanistas es la posibilidad de estudiar en detalle - y no sólo a través de los textos famosos- el impacto de América en la mentalidad europea conforme pasan las generaciones. Es un privilegio poder consultar a la vez, y cómodamente, las publicaciones culturales de los jesuitas del siglo xvin, como el Journal de Trévoux, muchas traducciones de obras que hablan de América y las varias ediciones sucesivas de las Lettres édifiantes et curieuses. Estas últimas recogen una selección de las "cartas anuas". Representan 34 tomos en la edición príncipe (1702-1774). La edición de 1781 establece una separación por zonas y los tomos 6 a 9 se dedican al continente americano. Las fechas y lugares de publicación, la selección, las traducciones en cadena, los prefacios, las cartas dedicatorias, los anexos a veces, todo puede ser significativo. Quien lee alemán puede completar su información en Chantilly leyendo no sólo lo que publican los alemanes en francés ${ }^{8}$, sino unas colecciones de testimonios germanos como las que compila Christoph-Gottlieb von Murr en la ciudad de Halle en 1809-18119.

La tarea de estudiar en el correr del tiempo las miradas cruzadas de unos sobre otros nos parece urgente. Así podremos corregir los viejos prejuicios. En las Memorias de Fray Servando Teresa de Mier, los "indios" somos nosotros, los europeos, y nos resulta muy útil. Las dos bibliotecas que presentamos brevemente no pueden competir, en nuestro terreno, con los grandes fon-

interesantes: por ejemplo nueve ediciones en cnatro idiomas de la Práctica dt la Theología Mystica de Miguel Godínez (el irlandés Wadding) publicada por primera vez en Sevilla, en 1682.

${ }^{8}$ Por ejemplo J. Stocklein, Lettres et voyages de missionnaires de la Compagnie de Jésus dans les deux Indes et autres pays d'Outre-mer, Augsburgo, 1736, 4 ts. in folio. Él mismo publica también textos en alemán que a veces son traducciones del francés. No se ha realizado todavía el "vaciado" de las obras colectivas para el fichero de autores de esta biblioteca, tampoco se ha empezado la informatización.

${ }^{9}$ Nachrichten von verschieden Ländern des spanischen America: aus eigenhänder Auffsätzen einiger Missionäre der Gesellschaft Jesu... 
dos de los Estados Unidos, y menos con el Archivo de Indias de Sevilla, pero tienen vocación para aproximar a los habitantes de ambos continentes.

Marie-Cécile Bénassy-Berling Université de Paris III-Sorbonne Nouvelle 
